Published in final edited form as:

Coron Artery Dis. 2018 March ; 29(2): 104-113. doi:10.1097/MCA.0000000000000573.

\title{
Chronic Darapladib Use Does Not Affect Coronary Plaque Composition Assessed Using Multimodality Intravascular Imaging Modalities: A Randomized-Controlled Study
}

\author{
Woong Gil Choi ${ }^{1,2}$, Megha Prasad ${ }^{1}$, Ryan Lennon, MS ${ }^{1}$, Rajiv Gulati ${ }^{1}$, Abhiram Prasad ${ }^{1}$, \\ Lilach O. Lerman ${ }^{1}$, and Amir Lerman ${ }^{1,3}$ \\ ${ }^{1}$ Department of Cardiovascular Diseases, Mayo Clinic, 200 First Street SW, Rochester, MN \\ 55905, United States \\ ${ }^{2}$ Division of Cardiology, Department of Internal Medicine, Konkuk University College of Medicine, \\ Chungbuk, Korea \\ ${ }^{3}$ Division of Nephrology and Hypertension, Mayo Clinic, 200 First Street SW, Rochester, MN \\ 55905, United States
}

\begin{abstract}
Background-Lipoprotein associated phospholipase $\mathrm{A}_{2}\left(\mathrm{Lp}-\mathrm{PLA} \mathrm{A}_{2}\right)$ may play a role in plaque progression and vulnerability. We aimed to define plaque characteristics on multimodality intravascular imaging in patients with coronary endothelial dysfunction in response to chronic LpPLA2 inhibition by darapladib.

Methods-This is a double-blinded, randomized study screening 70 patients, and enrolling 54 patients with suspected ischemia, without obstructive disease on angiography and with coronary endothelial dysfunction by invasive assessment. Patients were randomized to receive darapladib or placebo for 6 months. Forty patients underwent multimodality intravascular imaging at baseline and post- 6 months of therapy. Several parameters of plaque vulnerability were measured, including maximum value of lipid core burden index for any of the 4-mm segment (maxLCBI ${ }_{4 \mathrm{~mm}}$ ) by near-infrared spectroscopy. Microchannels and macrophages were assessed using optical coherence tomography and necrotic core volume by virtual histology intravascular ultrasound.
\end{abstract}

Results-There was no significant difference in $\operatorname{maxLCBI}_{4 \mathrm{~mm}}(64.56[7.74,128.56]$ vs. 22.43 $[0,75.63], \mathrm{p}=0.522)$ or in macrophage images angle $\left(-9.5^{\circ}[-25.53,12.68]\right.$ vs $-16.7^{\circ}[-28.6$, $-4.8], \mathrm{p}=0.489)$ between groups. There was a trend towards shorter microchannel length in the darapladib arm $(0 \mathrm{~mm},[-4.4,0.2]$ vs $0.8 \mathrm{~mm}[-0.15,1.9], \mathrm{p}=0.08)$. Percentage of necrotic core volume was not significantly different.

\footnotetext{
Address correspondence to: Amir Lerman, MD, Mayo Clinic, 200 First St SW, Rochester MN 55905, lerman.amir@mayo.edu. Clinicaltrials.gov Identifier: NCT01067339

Disclosures: Dr. Amir Lerman is a member of the advisory board of Itamar Medical, a company that produces EndoPAT, a device for noninvasive endothelial function detection. This device was not used in this study. Dr. Lilach O Lerman is his spouse.

GSK provided blinded study medication that was either darapladib or placebo, and provided funding for OCT catheters and investigator/staff time.
} 
Conclusions-Thus, chronic inhibition of endogenous Lp-PLA 2 activity with darapladib was not associated with a change in plaque progression and vulnerability indices after six months of therapy and the endogenous LpPLA 2 pathway may not play a direct role in the progression of early atherosclerosis in humans.

\section{Keywords}

Lipoprotein associated phospholipase $\mathrm{A}_{2}$; atherosclerosis; Intracoronary imaging; intravascular imaging; darapladib

\section{Introduction}

Lipoprotein associated phospholipase $\mathrm{A}_{2}\left(\mathrm{Lp}-\mathrm{PLA}_{2}\right)$ is a novel biomarker for vascular wall inflammation that is bound to both low density and high density lipoprotein, and has been shown to promote vascular inflammation ${ }^{1}$. Epidemiological studies have suggested that Lp$\mathrm{PLA}_{2}$ is a potential independent risk factor for cardiovascular events ${ }^{2-6}$ possibly through a causative role in the atherosclerotic process, explaining the increased cardiovascular morbidity and mortality seen with increased Lp-PLA 2 levels. Moreover, Lp-PLA 2 may play a role in vascular inflammation in the early stage of atherosclerosis, as it has been directly related to the extent of atheroma and strongly associated with coronary endothelial function $^{7-9}$. This suggests a potential mechanistic link between inflammation, coronary endothelial function and Lp-PLA 2 levels in early atherosclerosis.

Darapladib, a selective reversible Lp-PLA 2 inhibitor, was developed with the goal of targeting Lp-PLA $\mathrm{A}_{2}$ and reducing cardiovascular events. Previous studies demonstrated that inhibition of Lp-PLA 2 in the animal model of advanced atherosclerosis attenuated plaque progression ${ }^{10}$ and the progression of necrotic core in patients with coronary atherosclerosis 11. However, the effect of darapladib on early atherosclerosis has yet to be further explored.

The current study was designed to assess the role of Lp-PLA 2 in coronary plaque progression and stability in patients with early coronary atherosclerosis. We hypothesized that in patients with early coronary atherosclerosis, structural and mechanical properties reflecting plaque vulnerability may be attenuated with darapladib. To this end, the present study investigated the changes in coronary plaque characteristics related to Lp-PLA 2 inhibition using intravascular imaging including near-infrared spectroscopy (NIRS), optical coherence tomography (OCT), and virtual histology intravascular ultrasound (VH-IVUS).

\section{Materials and Methods}

\section{Study Design}

This study was a single center, National Institutes of Health (NIH) funded, phase III, randomized, double-blinded controlled trial, performed between February 2010 and February 2015, that evaluated the effect of darapladib (GlaxoSmithKline; Brentford, London), an Lp-PLA 2 inhibitor, on plaque characteristics suggestive of plaque vulnerability. All patients provided informed consent and the Mayo Institutional Review Board approved the study protocol. 
Patients enrolled underwent baseline laboratory testing, including fasting lipid panel, liver and renal function testing, and index coronary angiography with intravascular imaging, and were then randomized by a statistical program to darapladib $160 \mathrm{mg}$ taken by mouth once per day. or placebo produced by pharmacy. Patients were followed for 6 months, and then reevaluated on follow-up with coronary angiography including intravascular imaging and repeat laboratory testing. The Mayo Clinic Institutional Review Board approved this study. This work was supported by the National Institutes of Health (NIH Grants HL-92954, AG-31750, DK20092, and DK102325), and GlaxoSmithKline provided the study drug darapladib and the placebo medication.

\section{Study population}

Patients were enrolled from the Chest Pain and Coronary Physiology Clinic as well as the outpatient and inpatient practices in the Cardiovascular Department at Mayo Clinic Rochester. Eligibility criteria included patients greater than 18 years of age, less than 85 years old, with a clinical indication for index coronary angiography and no significant coronary disease noted on angiography. Exclusion criteria included heart failure, ejection fraction $<40 \%$, unstable angina, myocardial infarction or angioplasty within 6 months prior to entry into the study, use of investigational agents within 1 month of entry into the study, patients who required treatment with positive inotropic agents other than digoxin during the study, patients with cerebrovascular accident within 6 months prior to entry the study, significant endocrine, hepatic or renal, disorders, local or systemic infectious disease within 4 weeks prior to entry into study, pregnancy or lactation, mental instability, and Federal Medical Center inmates.

Seventy patients were screened and of these 5 withdrew prior to randomization. Sixty five patients were randomized to either the placebo arm $(n=34)$ or the darapladib arm $(n=31)$. During the study period, 5 patients withdrew from the placebo arm and 6 patients from the darapladib arm. Of the remaining patients, a subset of 40 patients, 21 in the placebo arm and 19 in the darapladib arm, underwent concomitant intracoronary imaging at baseline and follow-up. There were no significant differences between reasons for withdrawal from both arms. Reasons included needing spinal cord stimulator due to continued refractory angina and ineffectiveness of traditional clinical medications, concern that participation in the study would put professional federal aviation licensure in jeopardy, and logistic concerns with travel to and from the clinic.

NIRS, OCT and VH-IVUS were performed for at least mild lesions of the left anterior descending (LAD) artery. At 6 months, NIRS, OCT and VH-IVUS examinations were repeated in the same segments as those imaged at baseline. All images were analyzed by the independent core laboratory at Mayo Clinic. Image review and analysis were performed by independent examiner who was blind to clinical characteristics and treatment arm.

\section{Near-infrared spectroscopy}

A coronary artery segment was identified between the proximal and mid-LAD using distance from anatomical landmarks such as side branches that are seen on angiography. We have previously reported the presence of lipid core in patients with early coronary 
atherosclerosis ${ }^{12}$.Subsequently, for each identified segment NIRS examination was performed. The NIRS system consists of $3.2 \mathrm{Fr}, 160 \mathrm{~cm}$ rapid exchange catheter (LipiScan, InfraReDx, Burlington, MA, USA), a motorized pullback device and a console ${ }^{13-15}$. NIRS catheter was introduced into the LAD over a 0.014-inch coronary guidewire and pulled back using an automated mechanical pullback and rotation device at a speed of $0.5 \mathrm{~cm} / \mathrm{s}$ and 240 rotation/m until the NIRS catheter was withdrawn into the guiding catheter. The NIRS images and the block chemograms were recorded to a compact disk for offline quantitative analysis. The analysis was performed using the LipiScan analyzer software (LipiScan, InfraReDx, Burlington, MA, USA). The NIRS system acquires about 1000 NIRS measurement/12.5 cm of artery scanned and determines the presence of lipid core plaque (LCP) at each interrogated location in the artery using a predictive algorithm. The calculated data are displayed in a two-dimensional map of the vessel ('chemogram'). The x-axis of the chemogram represents the pullback position in millimeter scale and the y-axis represents the circumferential position in degrees $\left(0-360^{\circ}\right)$; a color scale from red to yellow indicates increasing algorithm probability that an LCP is present ${ }^{12,13}$. From the chemogram, a summary metric of the probability that an LCP is present in a 2-mm interval of pullback is computed and displayed in a color map called a 'block chemogram'. The block chemogram is mapped to the same color scale as the chemogram, but the display is binned to four discrete colors to aid visual interpretation (red: $\mathrm{P}<0.57$, orange: $0.57 \leq \mathrm{P} \leq 0.84$, tan:0.84 $\leq \mathrm{P}$ $\leq 0.98$, yellow: $\mathrm{P}>0.98$, algorithm probability that an LCP is present in that $2 \mathrm{~mm}$ block). To provide a quantitative summary metric of the LCP presence in the entire scanned segment, the lipid core burden index (LCBI) was calculated, which is the fraction of valid pixel in the chemogram that exceeds an LCP probability of 0.6 , multiplied by 1000 . Because LCBI is dependent on the length of the artery scanned, LCBI per length of the scanned artery (LCBI/L) was also analyzed in the present study. The maxLCBI $4 \mathrm{~mm}$ was defined as the maximum value of the LCBI for any of the $4 \mathrm{~mm}$ segment in the interrogated region and used as the index representing the size of the LCP.

\section{Virtual Histology Intravascular ultrasound}

The methods of the IVUS examination have been described previously, and we have previously reported the presence of necrotic core in patients with early atherosclerosis 15,16 . The IVUS examination was performed after intracoronary administration of 100-200 mg nitroglycerine. A 20-MHz, 2.9F monorail, electronic Eagle Eye Gold IVUS catheter (Volcano Therapeutics Rancho Cordova, CA) was advanced into the LAD and automatic pullback at $0.5 \mathrm{~mm} / \mathrm{s}$ was performed. The four VH-IVUS plaque components were colorcoded as follows: dark green (fibrous), light green (fibrofatty), red (necrotic core), and white (dense calcium), and are reported as the area or percentage of plaque area. All imaging data were stored digitally in a dedicated console (In-Vision Gold, Volcano Therapeutics, Rancho Cordova, CA). Patients were scheduled to undergo IVUS of the same study vessel at 6 months. Volumetric IVUS data was presented as total volume per lesion length $\left(\mathrm{mm}^{3} / \mathrm{mm}\right)$ for correcting the differences of lesion length among the subjects.

\section{OCT image acquisition and analysis}

For acquisition of OCT images, C7-XR OCT Intravascular Imaging System (St Jude Medical, St Paul, MN) was used. The intracoronary OCT technique has been described 
previously ${ }^{17-20}$. Imaging catheter (Dragonfly, St Jude Medical, St. Paul, MN) was advanced into the proximal mid segment of the LAD, and automatic pull-back at a speed of $20 \mathrm{~mm} / \mathrm{sec}$ (100 frames/sec) was initiated in concordance with blood clearance by infusion of contrast media. All OCT images were digitally stored and analyzed offline using proprietary software (St Jude Medical). Each segment was evaluated in terms of plaque type and additional 2 OCT-based characteristics including macrophage image and microchannels. Plaques were classified into 3 categories according to plaque type: lipid, calcific or fibrous 21. A lipid plaque has low signal region with diffuse border. A plaque with lipid occupying two or more quadrants of any cross-sectional area within the plaque was considered as a lipid-rich plaque. A fibrous plaque was defined as a lesion with homogeneous high backscattering region. A calcified plaque was defined as a lesion with a signal-poor or heterogeneous region with a sharply delineated border. Macrophage image was defined as signal-rich distinctor confluent punctate regions that exceed the intensity of background speckle noise, which are accompanied by high behind signal attenuation ${ }^{22,23}$. In plaques with macrophage image, angles of macrophage arc were measured using a protractor centered on the lumen at every frame. Maximum angle and longitudinal length were recorded. Microchannels were defined as intraplaque signal-voiding tubular structures with a diameter of 50-300 $\mu \mathrm{m}$ which were sharply delineated and identified on more than three consecutive cross-sectional OCT images. Maximum number and longitudinal length of microchannels were measured $17,18,20,22,24$. Longitudinal length was measured on longitudinal view.

\section{Laboratory testing}

Patients underwent basic blood testing (complete blood count, serum electrolytes, lipid profile) as well as assessment of Lp-PLA 2 activity and high sensitivity C-reactive protein (hs-CRP) levels using baseline and follow-up stored samples. The latex particle-enhanced immunoturbidimetric assay(Roche Diagnostics, Indianapolis, IN) was used to measure hsCRP, while an enzymatic colorimetric activity assay (Diazyme Laboratories, Poway, CA) with a 5-point calibration curve $(0-400 \mathrm{nmol} / \mathrm{min} / \mathrm{mL})$ on the Cobas 6000/c501 instrument (Roche Diagnostics, Indianapolis, IN) was used to measure Lp-PLA 2 activity.

\section{Statistical analysis}

Statistical analysis was performed using the JMP 8.0 Software and SAS 9.3 (SAS Institute, Cary, NC, USA). Continuous variables were presented as mean \pm standard deviation if normally distributed and were compared with the unpaired Student's $t$ test. Variables not normally distributed were presented as median (first, third quartile) and compared with the Mann-Whitney rank-sum test. Categorical variables were presented as frequency (percentage) and compared with Pearson's $\mathrm{x} 2$ test. Comparison within the groups were done using Wilcoxon signed rank test for non-parametric data. The intraagreement (Kappa) was calculated to present the intra-observer variability for identification of microchannel on OCT and intra-class correlation coefficient were used to describe intra-observer reproducibility for plaque volume on VH-IVUS. All statistical tests were two-sided and a P-value, 0.05 was considered to be statistically significant. 


\section{Results \\ Baseline characteristics}

Mean age of patients in the darapladib and placebo group was $54.7 \pm 11.2$ and $52.9 \pm 10.1$ years, respectively (Table 1). Baseline characteristics are listed in Table 1. Other than baseline LDL, there was no significant difference in medication use (Table 1), or baseline laboratory values in both groups ( $>0.05$ ) (Table 2).

On follow-up there was no significant difference in total cholesterol level, LDL levels or hsCRP levels, but there was a significant decrease in Lp-PLA 2 activity levels and a greater increase in HDL in the darapladib compared to the placebo group ( $p<0.001)$ (Table 3)

Overall, there were no safety concerns with no deaths. There were five serious adverse events, including a patient with chest pain who was admitted and recuperated with nitroglycerin, another with recurrent angina secondary to anomalous pulmonary vein and endothelial dysfunction, a third requiring preponement of tricuspid valve repair and anomalous pulmonary vein repair secondary to chest pain and a patient with chest pain who required angiography. Independent review suggested none of the events were related to the study drug.

\section{Near Infrared Spectroscopy}

There was no significant difference in mean length of the LAD interrogated by NIRS pullback $(56.92 \pm 16.30 \mathrm{~mm}$ vs $62.68 \pm 20.11 \mathrm{~mm} ; \mathrm{p}=0.450)$. In the analysis of chemogram, there were no significant differences in overall LCBI, LCBI/L and maxLCBI $4 \mathrm{~mm}$ between both groups at baseline and at 6 month follow-up (Table 4). In patients with repeat NIRS, $\mathrm{LCBI} / \mathrm{L}$ and $\operatorname{maxLCBI}{ }_{4 \mathrm{~mm}}$ were not significantly changed $[0.29[-0.47,1.28], \mathrm{p}=0.383$, $-31.50[-69.62,49.79], \mathrm{p}=0.547$ for darapladib, $-0.19[-0.70,1.12], \mathrm{p}=0.578,-64.56$ $[-133.90,0], p=0.063$ for placebo, respectively] (Figure 1). There were no significant changes in median percentage of color blocks including yellow, tan, orange, and red blocks, respectively. NIRS findings at baseline and follow-up are detailed in Table 4.

\section{VH-IVUS}

At baseline and follow up, plaque volume and necrotic core component measurements were comparable between treatment groups in the region of interests (Table 5). Corrected plaque volume and necrotic core volume were not significantly different during the follow up period within those receiving darapladib and placebo $(3.13[3.69,4.34]$ vs $4.53[4.16,6.67]$ $\mathrm{mm}^{3} / \mathrm{mm}$ at baseline, $\mathrm{p}=0.070 ; 3.60[3.11,5.81]$ vs $4.45[3.08,6.79]$ at follow up, $\mathrm{p}=$ 0.443 , respectively), When we analyzed changes of atheroma volume and percentage of necrotic core component, we found no significant change in corrected plaque volume $\left(-0.11[-0.84,0.28] \mathrm{mm}^{3} / \mathrm{mm}, \mathrm{p}=0.421\right.$ for darapladib, $-0.08[-0.40,0.43] \mathrm{mm}^{3} / \mathrm{mm}, \mathrm{p}=$ 0.358 for placebo, respectively) and percentage of necrotic core component $(0 \%[-4.60,5.4]$, $\mathrm{p}=0.835$ for darapladib, $0.15 \%$ [-2.43, 0.875$], \mathrm{p}=0.915$ for placebo, respectively) within the comparison of both groups (Figure 2). 
We also analyzed difference between group in absolute changes and percent change between baseline and 6 months. There were no significant difference in absolute change of corrected $\mathrm{PV}$, percent change of corrected $\mathrm{PV}$, absolute change of $\mathrm{NC}$ component volume and percent change of NC component volume (Table 5).

\section{OCT}

OCT findings at baseline and follow-up are shown in Table 7.The OCT imaging demonstrated about $91 \%$ vs $88 \%$ of lipid-rich plaques, $27 \%$ vs $50 \%$ of macrophage images and $64 \%$ vs $63 \%$ of microchannel in darapladib and placebo group, respectively at baseline. There were no significant differences in lipid rich plaque angle, macrophage image, and microchannel between 2 groups at baseline and follow up. Changes in parameters describing plaque vulnerability were non-significant. Macrophage images angle $\left(-9.5^{\circ}[-25.53,12.68]\right.$ vs $\left.-16.7^{\circ}[-28.6,-4.8], \mathrm{p}=0.489\right)$ was not significantly different in both groups but microchannel length $(0 \mathrm{~mm},[-4.4,0.2]$ vs $0.8 \mathrm{~mm}[-0.15,1.9], \mathrm{p}=0.08)$ showed a trend toward shorter length in darapladib group compared with placebo group.

\section{Intra-observer variability}

Kappa coefficient for the presence or absence of microchannel by OCT was 0.77 (95\% CI 0.35 to 1.00 ) and intra class correlation coefficient for plaque volume by VH-IVUS was 0.88 (95\% CI 0.70 to 0.95 ).

\section{Discussion}

The current study demonstrates that six months of endogenous Lp-PLA 2 inhibition does not affect the degree of atherosclerosis or plaque characteristics in patients with early coronary atherosclerosis. The current study therefore does not support a role for Lp-PLA 2 inhibition in attenuating atherosclerotic plaque progression in humans.

Darapladib was not associated with a change in lipid core burden by NIRS, atheroma volume and necrotic core proportion as measured by VH-IVUS and micro-environment like macrophage, and microchannel by OCT showed no significant improvement on follow-up.

Preliminary data supported potential role of $\mathrm{Lp}-\mathrm{PLA}_{2}$ in the pathogenesis of atherosclerosis due to its role in inflammation ${ }^{1}$. In particular, $\mathrm{Lp}-\mathrm{PLA}_{2}$ could have played a role in early atherosclerosis. Previous studies from our group and others have demonstrated that early coronary atherosclerosis is associated with elevated Lp-PLA 2 levels and enhanced activity of Lp-PLA $_{2}$ across the coronary circulation, supporting a particular role for this molecule in early coronary atherosclerosis $8,9,25$. In a study of patients with early coronary atherosclerosis undergoing coronary endothelial function testing, abnormal coronary vasoreactivity, an early marker of atherosclerosis, was found to be strongly associated with elevated Lp-PLA 2 levels ${ }^{26}$. While there is strong evidence consistent with a role for Lp$\mathrm{PLA}_{2}$ in this early process, we found that Lp-PLA 2 inhibition did not affect early atherosclerotic plaques in our study. This is consistent with results from two large randomized clinical trials did not show a reduction in major coronary events with darapladib inhibition ${ }^{27,28}$.These studies investigated the clinical efficacy and safety of darapladib on a background of optimal medical therapy in patients with stable coronary heart disease and 
acute coronary syndrome, respectively. However, darapladib was not not associated with reduction in the primary endpoint of major adverse cardiovascular events in one study, and major coronary events or in major adverse cardiovascular events in post- acute coronary syndrome patients.

We explored the role of darapladib in altering plaque characteristics by analyzing atheroma through multiple imaging modalities. During Lp-PLA 2 inhibition, (1) lipid core burden analyzed by NIRS also remained without change. (2) Atheroma volume and necrotic core proportion observed by VH-IVUS did not change in most of the patients either. (3) Finally, micro-environmental features like macrophages, or microchannels by OCT showed no significant improvement in most of the patients. Previously, the IBIS-2 trial showed that Lp$\mathrm{PLA}_{2}$ inhibition over 12 months prevented necrotic core expansion, a key determinant of plaque vulnerability ${ }^{11}$. Necrotic core volume increased significantly during the study period among patients receiving placebo, but remained unchanged in the darapladib group. Lipid core was not improved with Lp-PLA 2 inhibition either. Our results are consistent with these data, except that necrotic core volume in our study did not change in placebo group. The LDL cholesterol level was relatively lower and HDL cholesterol level was higher in our patient population compared with those in the IBIS-2 trial population. In addition, a difference in follow-up interval may further account for the discrepancy in our findings. Notably, our study used multiple imaging modalities to identify the precise change of atherosclerotic plaque, which is a key strength, but none of them identified a prominent effect of the drug.

Intravascular imaging has played an important role in advancing our understanding of the pathophysiology of coronary artery plaque. NIR, OCT, VH-IVUS are representative and complementary tools of the coronary plaque imaging in clinical practice. VH-IVUS has been frequently used to obtain detailed information about the composition and characteristics of coronary atherosclerotic plaques ${ }^{29}$. The greatest advantage of OCT is its high-resolution images that can provide detailed observation of the vulnerable lipid core plaque. It characterizes not only plaque components but also coronary microstructures like macrophages and the vasa vasorum ${ }^{18,30}$. OCT especially has an important role in evaluating the vasa vasorum in early atherosclerosis ${ }^{31}$. The NIRS system excels in its ability to discriminate tissue type difference based on chemical composition in coronary autopsy specimens and in vivo validation studies ${ }^{13}$.Thus, NIRS has been proven to be the only available tool capable of reliably detecting the lipid core plaque.

In the present study, there were no changes in the atherosclerotic component of plaque by VH-IVUS, OCT and NIR. These results are consistent with larger randomized clinical studies that have also shown no reduction in major adverse cardiovascular events with Lp$\mathrm{PLA}_{2}$ inhibition. Our findings further underscore the multiple complex and redundant pathways involved in inflammation that make it difficult to target a particular component the atherosclerotic process.

Our data support adherence with the medication as there is significant reduction in Lp-PLA 2 activity in the darapladib arm. There was no significant reduction in hs-CRP levels with darapladib use, however, potentially suggesting that the degree of inhibition was insufficient 
to reduce hs-CRP levels and allow plaque attenuation. This is also consistent with larger randomized studies suggesting no improvement in cardiovascular outcomes with darapladib.

Our study has several strengths. This is the first pathophysiologic study examining the effect of darapladib on plaque composition in patients with coronary endothelial dysfunction and is an important addition exploring the mechanistic aspects of Lp-PLA2 to the clinical trials.

Secondly, the prospective randomized nature of our study and the scientific rigor with which the study was conducted confer high validity. Third, unlike many previous studies, we have been able to ascertain medication adherence by assessing the degree of Lp-PLA $\mathrm{A}_{2}$ inhibition. Fourth, while each intravascular imaging modality has its own strengths and weaknesses, our study uses three separate imaging modalities in conjunction with an experienced core laboratory to optimize yield of reproducible and generalizable results.

\section{Study limitations}

In turn, our study has several limitations. First, our sample size is small, and may limit our findings. Second, this is a single-center study with a limited follow-up interval of 6 months, potentially reducing the detectability of beneficial effect. Third, patients were not recruited based on their baseline Lp-PLA 2 activity levels, which might have helped in appropriate screening and randomization of patients. Also, while VH-IVUS was used extensively in previous large studies such as PROSPECT, its use in clinical practice is declining ${ }^{32}$. While the evaluating macropahges and microchannels with OCT has been studied, it is difficult and there are potential pitfalls which may limit interpretation and reproducibility. Additionally the diagnostic accuracy for OCT-derived macrophages was not higher than expected, and thus the ability of OCT to accurately characterize macrophages needs to be further investigated and clarified in future studies. This is an inherent limitation of OCT that needs to be further evaluated. The study of macrophages and microchannels with OCT can pose several difficulties and this must be kept in mind as we interpret images and may affect reproducibility of data. ${ }^{334,35}$ This is an inherent limitation to this methodology.

\section{Conclusion}

Lp-PLA 2 has been associated with vascular inflammation, early atherosclerosis and cardiovascular disease. The current study demonstrates that 6 months of $\mathrm{LPPLA}_{2}$ inhibition did not change plaque volume or composition, including lipid core burden and plaque vulnerability, when analyzed with multimodality intravascular imaging. These findings do not support the role of $\mathrm{LpPLA}_{2}$ inhibition in attenuating atherosclerotic plaque progression in humans.

\section{Supplementary Material}

Refer to Web version on PubMed Central for supplementary material.

\section{Acknowledgments}

Sources of Funding: This work was supported by the National Institutes of Health (NIH Grants HL-92954, AG-31750, DK20092, and DK102325), and the Mayo Foundation. GlaxoSmithKline provided the study drug darapladib. 


\section{References}

1. Zalewski A, Macphee C. Role of lipoprotein-associated phospholipase A2 in atherosclerosis: biology, epidemiology, and possible therapeutic target. Arterioscler Thromb Vasc Biol. 2005; 25:923-31. [PubMed: 15731492]

2. O'Donoghue M, Morrow DA, Sabatine MS, Murphy SA, McCabe CH, Cannon CP, Braunwald E. Lipoprotein-associated phospholipase A2 and its association with cardiovascular outcomes in patients with acute coronary syndromes in the PROVE IT-TIMI 22 (PRavastatin Or atorVastatin Evaluation and Infection Therapy-Thrombolysis In Myocardial Infarction) trial. Circulation. 2006; 113:1745-52. [PubMed: 16537575]

3. Sabatine MS, Morrow DA, O'Donoghue M, Jablonksi KA, Rice MM, Solomon S, Rosenberg Y, Domanski MJ, Hsia J. Prognostic utility of lipoprotein-associated phospholipase A2 for cardiovascular outcomes in patients with stable coronary artery disease. Arterioscler Thromb Vasc Biol. 2007; 27:2463-9. [PubMed: 17766330]

4. Blake GJ, Dada N, Fox JC, Manson JE, Ridker PM. A prospective evaluation of lipoproteinassociated phospholipase A(2) levels and the risk of future cardiovascular events in women. J Am Coll Cardiol. 2001; 38:1302-6. [PubMed: 11691499]

5. Koenig W, Twardella D, Brenner H, Rothenbacher D. Lipoprotein-associated phospholipase A2 predicts future cardiovascular events in patients with coronary heart disease independently of traditional risk factors, markers of inflammation, renal function, and hemodynamic stress. Arterioscler Thromb Vasc Biol. 2006; 26:1586-93. [PubMed: 16627803]

6. Garza CA, Montori VM, McConnell JP, Somers VK, Kullo IJ, Lopez-Jimenez F. Association between lipoprotein-associated phospholipase A2 and cardiovascular disease: a systematic review. Mayo Clin Proc. 2007; 82:159-65. [PubMed: 17290721]

7. Garg PK, McClelland RL, Jenny NS, Criqui M, Liu K, Polak JF, Jorgensen NW, Cushman M. Association of lipoprotein-associated phospholipase A(2) and endothelial function in the MultiEthnic Study of Atherosclerosis (MESA). Vasc Med. 2011; 16:247-52. [PubMed: 21708876]

8. Lavi S, Lavi R, McConnell JP, Lerman LO, Lerman A. Lipoprotein-associated phospholipase A(2) : review of its role as a marker and a potential participant in coronary endothelial dysfunction. Mol Diagn Ther. 2007; 11:219-26. [PubMed: 17705576]

9. Lavi S, McConnell JP, Rihal CS, Prasad A, Mathew V, Lerman LO, Lerman A. Local production of lipoprotein-associated phospholipase A2 and lysophosphatidylcholine in the coronary circulation: association with early coronary atherosclerosis and endothelial dysfunction in humans. Circulation. 2007; 115:2715-21. [PubMed: 17502572]

10. Wilensky RL, Shi Y, Mohler ER 3rd, Hamamdzic D, Burgert ME, Li J, Postle A, Fenning RS, Bollinger JG, Hoffman BE, Pelchovitz DJ, Yang J, Mirabile RC, Webb CL, Zhang L, Zhang P, Gelb MH, Walker MC, Zalewski A, Macphee CH. Inhibition of lipoprotein-associated phospholipase A2 reduces complex coronary atherosclerotic plaque development. Nat Med. 2008; 14:1059-66. [PubMed: 18806801]

11. Serruys PW, Garcia-Garcia HM, Buszman P, Erne P, Verheye S, Aschermann M, Duckers H, Bleie O, Dudek D, Botker HE, von Birgelen C, D'Amico D, Hutchinson T, Zambanini A, Mastik F, van Es GA, van der Steen AF, Vince DG, Ganz P, Hamm CW, Wijns W, Zalewski A, Integrated B and Imaging Study I. Effects of the direct lipoprotein-associated phospholipase A(2) inhibitor darapladib on human coronary atherosclerotic plaque. Circulation. 2008; 118:1172-82. [PubMed: 18765397]

12. Choi BJ, Prasad A, Gulati R, Best PJ, Lennon RJ, Barsness GW, Lerman LO, Lerman A. Coronary endothelial dysfunction in patients with early coronary artery disease is associated with the increase in intravascular lipid core plaque. Eur Heart J. 2013; 34:2047-54. [PubMed: 23569198]

13. Gardner CM, Tan H, Hull EL, Lisauskas JB, Sum ST, Meese TM, Jiang C, Madden SP, Caplan JD, Burke AP, Virmani R, Goldstein J, Muller JE. Detection of lipid core coronary plaques in autopsy specimens with a novel catheter-based near-infrared spectroscopy system. JACC Cardiovasc Imaging. 2008; 1:638-48. [PubMed: 19356494]

14. Choi BJ, Prasad A, Gulati R, Best PJ, Lennon RJ, Barsness GW, Lerman LO, Lerman A. Coronary endothelial dysfunction in patients with early coronary artery disease is associated with the increase in intravascular lipid core plaque. Eur Heart J. 2013; 34:2047-54. [PubMed: 23569198] 
15. Bae JH, Kwon TG, Hyun DW, Rihal CS, Lerman A. Predictors of slow flow during primary percutaneous coronary intervention: an intravascular ultrasound-virtual histology study. Heart. 2008; 94:1559-64. [PubMed: 18381376]

16. Garcia-Garcia HM, Mintz GS, Lerman A, Vince DG, Margolis MP, van Es GA, Morel MA, Nair A, Virmani R, Burke AP, Stone GW, Serruys PW. Tissue characterisation using intravascular radiofrequency data analysis: recommendations for acquisition, analysis, interpretation and reporting. EuroIntervention : journal of EuroPCR in collaboration with the Working Group on Interventional Cardiology of the European Society of Cardiology. 2009; 5:177-89.

17. Aoki T, Rodriguez-Porcel M, Matsuo Y, Cassar A, Kwon TG, Franchi F, Gulati R, Kushwaha SS, Lennon RJ, Lerman LO, Ritman EL, Lerman A. Evaluation of coronary adventitial vasa vasorum using 3D optical coherence tomography--animal and human studies. Atherosclerosis. 2015; 239:203-8. [PubMed: 25618027]

18. Cassar A, Matsuo Y, Herrmann J, Li J, Lennon RJ, Gulati R, Lerman LO, Kushwaha SS, Lerman A. Coronary atherosclerosis with vulnerable plaque and complicated lesions in transplant recipients: new insight into cardiac allograft vasculopathy by optical coherence tomography. Eur Heart J. 2013; 34:2610-7. [PubMed: 23801824]

19. Kato K, Yonetsu T, Kim SJ, Xing L, Lee H, McNulty I, Yeh RW, Sakhuja R, Zhang S, Uemura S, Yu B, Mizuno K, Jang IK. Comparison of nonculprit coronary plaque characteristics between patients with and without diabetes: a 3-vessel optical coherence tomography study. JACC Cardiovasc Interv. 2012; 5:1150-8. [PubMed: 23174639]

20. Park KH, Sun T, Liu Z, Yang SW, Lennon RJ, Lerman LO, Kushwaha SS, Lerman A. Relationship between markers of plaque vulnerability in optical coherence tomography and atherosclerotic progression in adult patients with heart transplantation. J Heart Lung Transplant. 2016

21. Tearney GJ, Regar E, Akasaka T, Adriaenssens T, Barlis P, Bezerra HG, Bouma B, Bruining N, Cho JM, Chowdhary S, Costa MA, de Silva R, Dijkstra J, Di Mario C, Dudek D, Falk E, Feldman MD, Fitzgerald P, Garcia-Garcia HM, Gonzalo N, Granada JF, Guagliumi G, Holm NR, Honda Y, Ikeno F, Kawasaki M, Kochman J, Koltowski L, Kubo T, Kume T, Kyono H, Lam CC, Lamouche G, Lee DP, Leon MB, Maehara A, Manfrini O, Mintz GS, Mizuno K, Morel MA, Nadkarni S, Okura H, Otake H, Pietrasik A, Prati F, Raber L, Radu MD, Rieber J, Riga M, Rollins A, Rosenberg M, Sirbu V, Serruys PW, Shimada K, Shinke T, Shite J, Siegel E, Sonoda S, Suter M, Takarada S, Tanaka A, Terashima M, Thim T, Uemura S, Ughi GJ, van Beusekom HM, van der Steen AF, van Es GA, van Soest G, Virmani R, Waxman S, Weissman NJ, Weisz G. Consensus standards for acquisition, measurement, and reporting of intravascular optical coherence tomography studies: a report from the International Working Group for Intravascular Optical Coherence Tomography Standardization and Validation. Journal of the American College of Cardiology. 2012; 59:1058-72. [PubMed: 22421299]

22. Uemura S, Ishigami K, Soeda T, Okayama S, Sung JH, Nakagawa H, Somekawa S, Takeda Y, Kawata H, Horii M, Saito Y. Thin-cap fibroatheroma and microchannel findings in optical coherence tomography correlate with subsequent progression of coronary atheromatous plaques. Eur Heart J. 2012; 33:78-85. [PubMed: 21831910]

23. Tearney GJ, Yabushita H, Houser SL, Aretz HT, Jang IK, Schlendorf KH, Kauffman CR, Shishkov M, Halpern EF, Bouma BE. Quantification of macrophage content in atherosclerotic plaques by optical coherence tomography. Circulation. 2003; 107:113-9. [PubMed: 12515752]

24. Kitabata H, Tanaka A, Kubo T, Takarada S, Kashiwagi M, Tsujioka H, Ikejima H, Kuroi A, Kataiwa H, Ishibashi K, Komukai K, Tanimoto T, Ino Y, Hirata K, Nakamura N, Mizukoshi M, Imanishi T, Akasaka T. Relation of microchannel structure identified by optical coherence tomography to plaque vulnerability in patients with coronary artery disease. Am J Cardiol. 2010; 105:1673-8. [PubMed: 20538113]

25. Lavi S, Herrmann J, Lavi R, McConnell JP, Lerman LO, Lerman A. Role of lipoprotein-associated phospholipase A2 in atherosclerosis. Curr Atheroscler Rep. 2008; 10:230-5. [PubMed: 18489851]

26. Yang EH, McConnell JP, Lennon RJ, Barsness GW, Pumper G, Hartman SJ, Rihal CS, Lerman LO, Lerman A. Lipoprotein-associated phospholipase A2 is an independent marker for coronary endothelial dysfunction in humans. Arterioscler Thromb Vasc Biol. 2006; 26:106-11. [PubMed: 16239595] 
27. Investigators S, White HD, Held C, Stewart R, Tarka E, Brown R, Davies RY, Budaj A, Harrington RA, Steg PG, Ardissino D, Armstrong PW, Avezum A, Aylward PE, Bryce A, Chen H, Chen MF, Corbalan R, Dalby AJ, Danchin N, De Winter RJ, Denchev S, Diaz R, Elisaf M, Flather MD, Goudev AR, Granger CB, Grinfeld L, Hochman JS, Husted S, Kim HS, Koenig W, Linhart A, Lonn E, Lopez-Sendon J, Manolis AJ, Mohler ER 3rd, Nicolau JC, Pais P, Parkhomenko A, Pedersen TR, Pella D, Ramos-Corrales MA, Ruda M, Sereg M, Siddique S, Sinnaeve P, Smith P, Sritara P, Swart HP, Sy RG, Teramoto T, Tse HF, Watson D, Weaver WD, Weiss R, Viigimaa M, Vinereanu D, Zhu J, Cannon CP, Wallentin L. Darapladib for preventing ischemic events in stable coronary heart disease. N Engl J Med. 2014; 370:1702-11. [PubMed: 24678955]

28. O'Donoghue ML, Braunwald E, White HD, Lukas MA, Tarka E, Steg PG, Hochman JS, Bode C, Maggioni AP, Im K, Shannon JB, Davies RY, Murphy SA, Crugnale SE, Wiviott SD, Bonaca MP, Watson DF, Weaver WD, Serruys PW, Cannon CP, Investigators ST, Steen DL. Effect of darapladib on major coronary events after an acute coronary syndrome: the SOLID-TIMI 52 randomized clinical trial. JAMA. 2014; 312:1006-15. [PubMed: 25173516]

29. Nasu K, Tsuchikane E, Katoh O, Vince DG, Virmani R, Surmely JF, Murata A, Takeda Y, Ito T, Ehara M, Matsubara T, Terashima M, Suzuki T. Accuracy of in vivo coronary plaque morphology assessment: a validation study of in vivo virtual histology compared with in vitro histopathology. Journal of the American College of Cardiology. 2006; 47:2405-12. [PubMed: 16781367]

30. Choi BJ, Matsuo Y, Aoki T, Kwon TG, Prasad A, Gulati R, Lennon RJ, Lerman LO, Lerman A. Coronary endothelial dysfunction is associated with inflammation and vasa vasorum proliferation in patients with early atherosclerosis. Arterioscler Thromb Vasc Biol. 2014; 34:2473-7. [PubMed: 25234815]

31. Kwon TG, Lerman LO, Lerman A. The Vasa Vasorum in Atherosclerosis: The Vessel Within the Vascular Wall. Journal of the American College of Cardiology. 2015; 65:2478-80. [PubMed: 26065985]

32. Stone GW, Maehara A, Lansky AJ, de Bruyne B, Cristea E, Mintz GS, Mehran R, McPherson J, Farhat N, Marso SP, Parise H, Templin B, White R, Zhang Z, Serruys PW, Investigators P. A prospective natural-history study of coronary atherosclerosis. N Engl J Med. 2011; 364:226-35. [PubMed: 21247313]

33. Amano H, Koizumi M, Okubo R, Yabe T, Watanabe I, Saito D, Toda M, Ikeda T. Comparison of Coronary Intimal Plaques by Optical Coherence Tomography in Arteries With Versus Without Internal Running Vasa Vasorum. Am J Cardiol. 2017; 119:1512-1517. [PubMed: 28347486]

34. Taruya A, Tanaka A, Nishiguchi T, Matsuo Y, Ozaki Y, Kashiwagi M, Shiono Y, Orii M, Yamano T, Ino Y, Hirata K, Kubo T, Akasaka T. Vasa Vasorum Restructuring in Human Atherosclerotic Plaque Vulnerability A Clinical Optical Coherence Tomography Study. J Am Coll Cardiol. 2015; 65:2469-2477. [PubMed: 26065984]

35. Tearney GJ. OCT imaging of macrophages: a bright spot in the study of inflammation in human atherosclerosis. JACC Cardiovasc Imaging. 2015; 8:73-5. [PubMed: 25592697] 

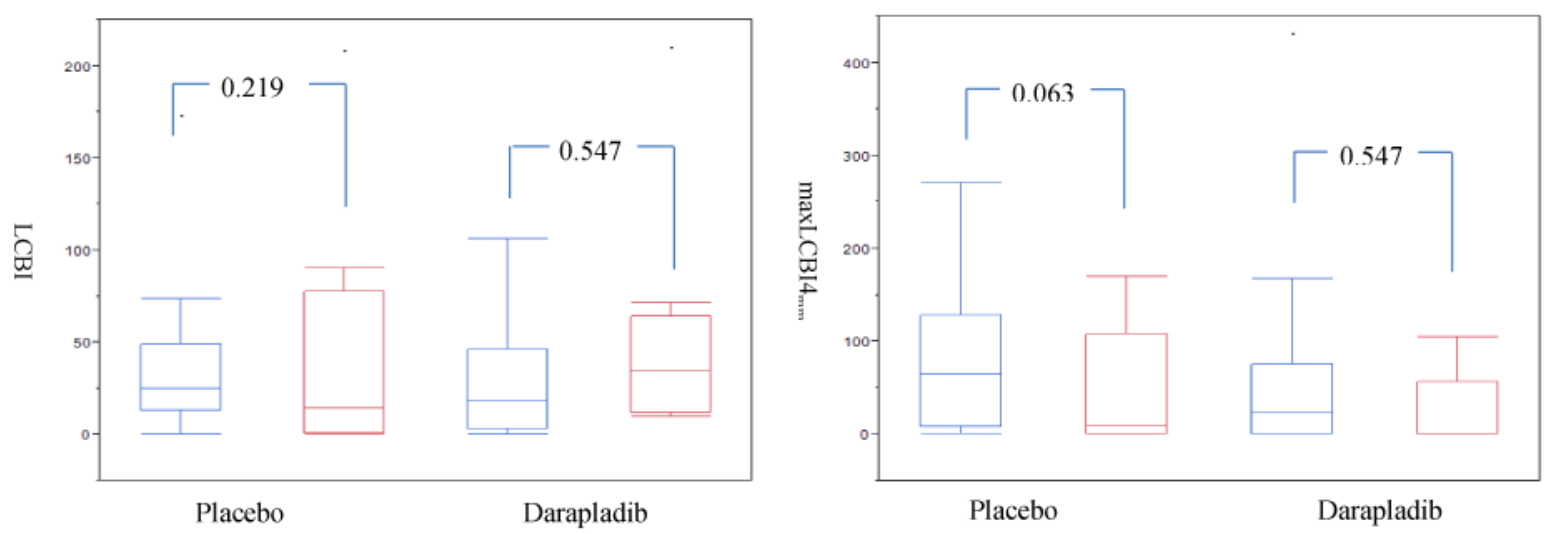

Figure 1. Changes of $\mathrm{LCBI}$ and $\operatorname{maxLCBI} \mathrm{Imm}_{4}$ within groups This figure shows that lipid core burden index/length (LCBI/L) (left) and maxLCBI ${ }_{4 m m}$ (right) were not significantly changed within the patients group with repeat near-infrared spectroscopy (NIRS) 

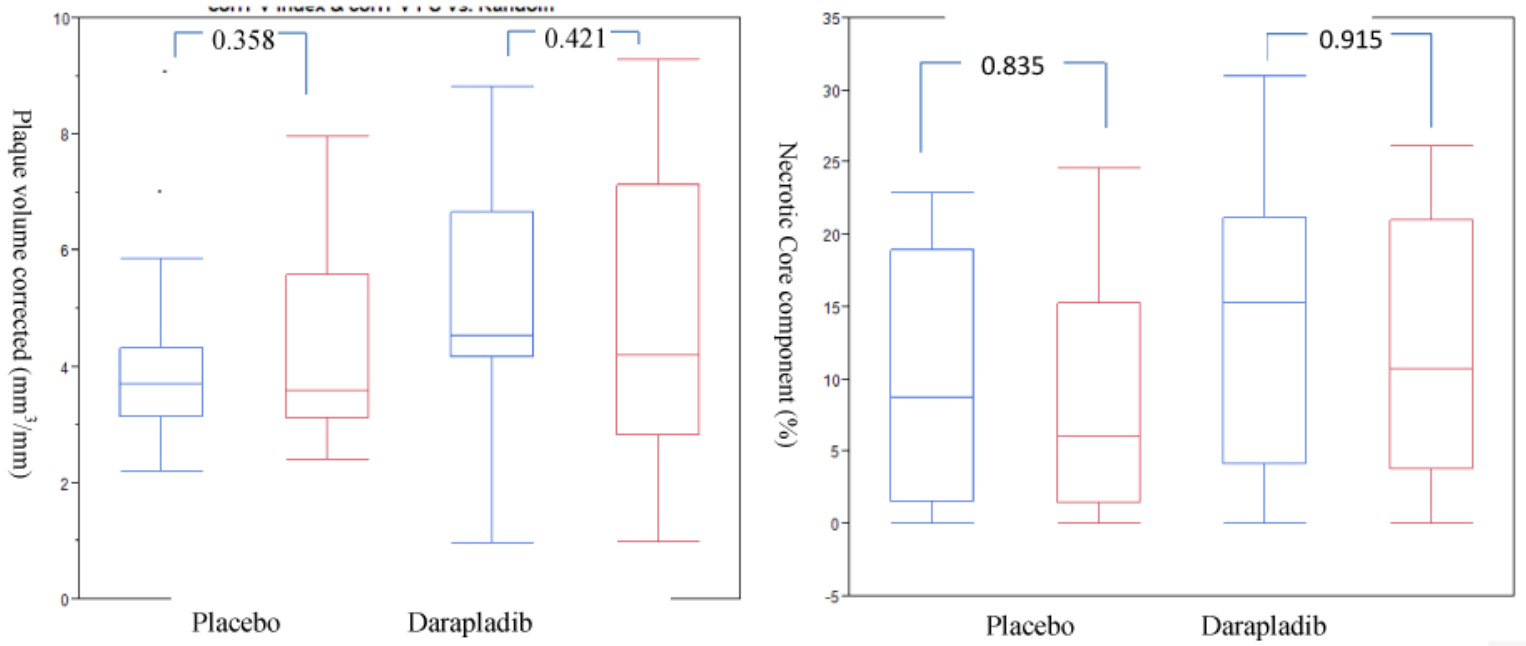

Figure 2. Change of corrected PV and percentage of necrotic core volume within groups This figure shows no significant change in corrected plaque volume (left) and percentage of necrotic core component (right) within patients groups. 

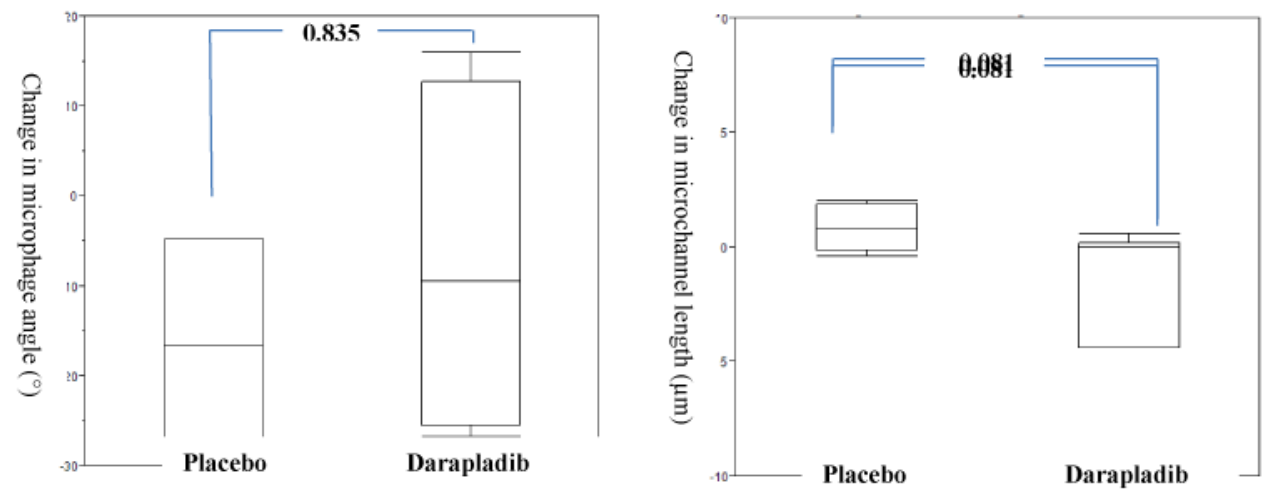

Figure 3. Change of macrophage angle and microchannel length within the groups

This figure shows that change in macrophage images angle was not significantly different in both groups (left) but change in microchannel length showed a trend toward shorter length in the darapladib group compared with placebo group (right). 
Table 1

Baseline characteristics

\begin{tabular}{|c|c|c|c|}
\hline & Placebo(21) & Darapladib(19) & $P$ value \\
\hline Age (years) & $52.9 \pm 10.1$ & $54.7 \pm 11.2$ & 0.176 \\
\hline $\operatorname{Sex}(M / F)$ & $1 / 20$ & $6 / 13$ & 0.742 \\
\hline Body Mass Index $\left(\mathrm{kg} / \mathrm{m}^{2}\right)$ & $30.3 \pm 7.8$ & $31.7 \pm 6.0$ & 0.199 \\
\hline Hypertension (\%) & $11(61)$ & $11(61)$ & 0.177 \\
\hline Diabetes $(\%)$ & $0(0)$ & $1(5)$ & 0.333 \\
\hline \multicolumn{4}{|l|}{ Smoking $(\%)$} \\
\hline Never smoked & $16(76)$ & $12(63)$ & 0.286 \\
\hline Former smoker & $5(24)$ & $7(37)$ & 0.286 \\
\hline Hyperlipidemia(\%) & $15(71)$ & $7(37)$ & 0.740 \\
\hline Family History & $14(67)$ & $9(47)$ & 0.397 \\
\hline \multicolumn{4}{|l|}{ Medications $(\%)$} \\
\hline Aspirin(\%) & $14(74)$ & $7(33)$ & 0.885 \\
\hline Beta blockers $(\%)$ & $5(24)$ & $7(37)$ & 0.286 \\
\hline RAS inhibitors(\%) & $4(19)$ & $6(32)$ & 0.361 \\
\hline $\mathrm{CCB}(\%)$ & $8(38)$ & $9(47)$ & 0.188 \\
\hline Lipid lowering drug use $(\%)$ & $8(37)$ & $6(32)$ & 0.137 \\
\hline
\end{tabular}

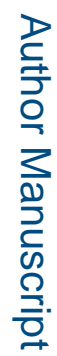

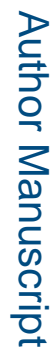

Coron Artery Dis. Author manuscript; available in PMC 2019 March 01. 

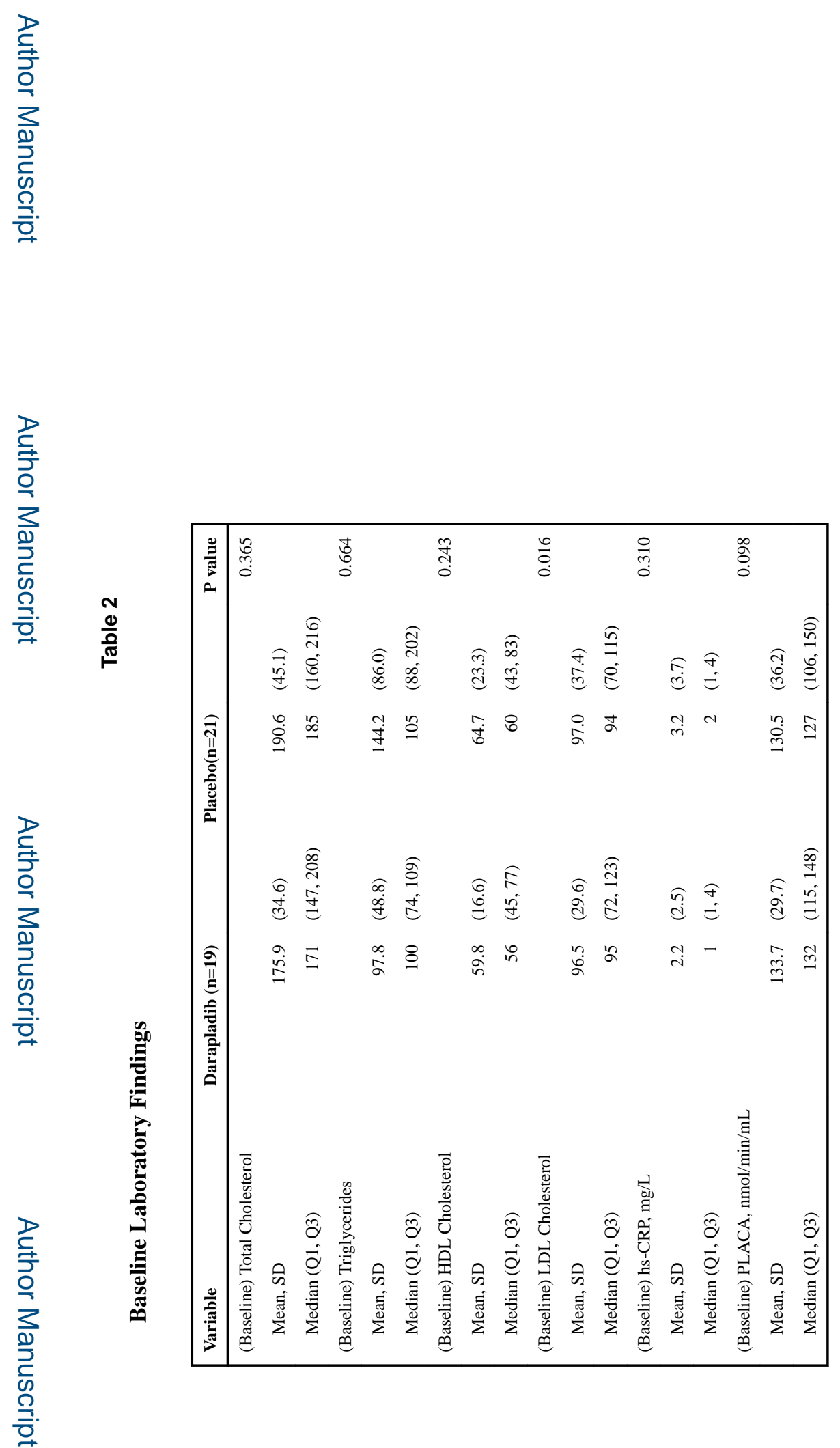

Coron Artery Dis. Author manuscript; available in PMC 2019 March 01. 


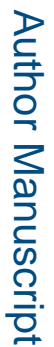

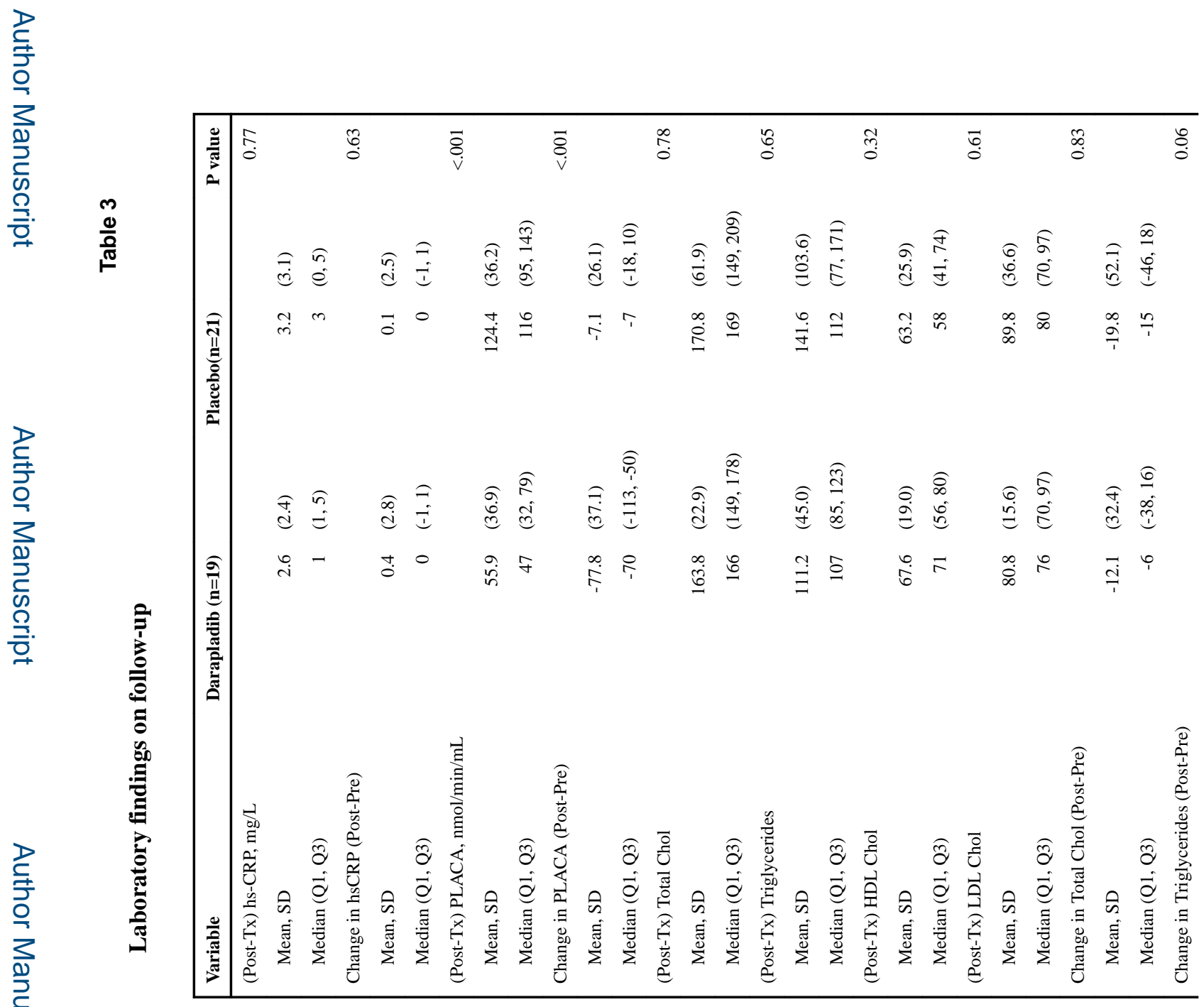

Coron Artery Dis. Author manuscript; available in PMC 2019 March 01. 

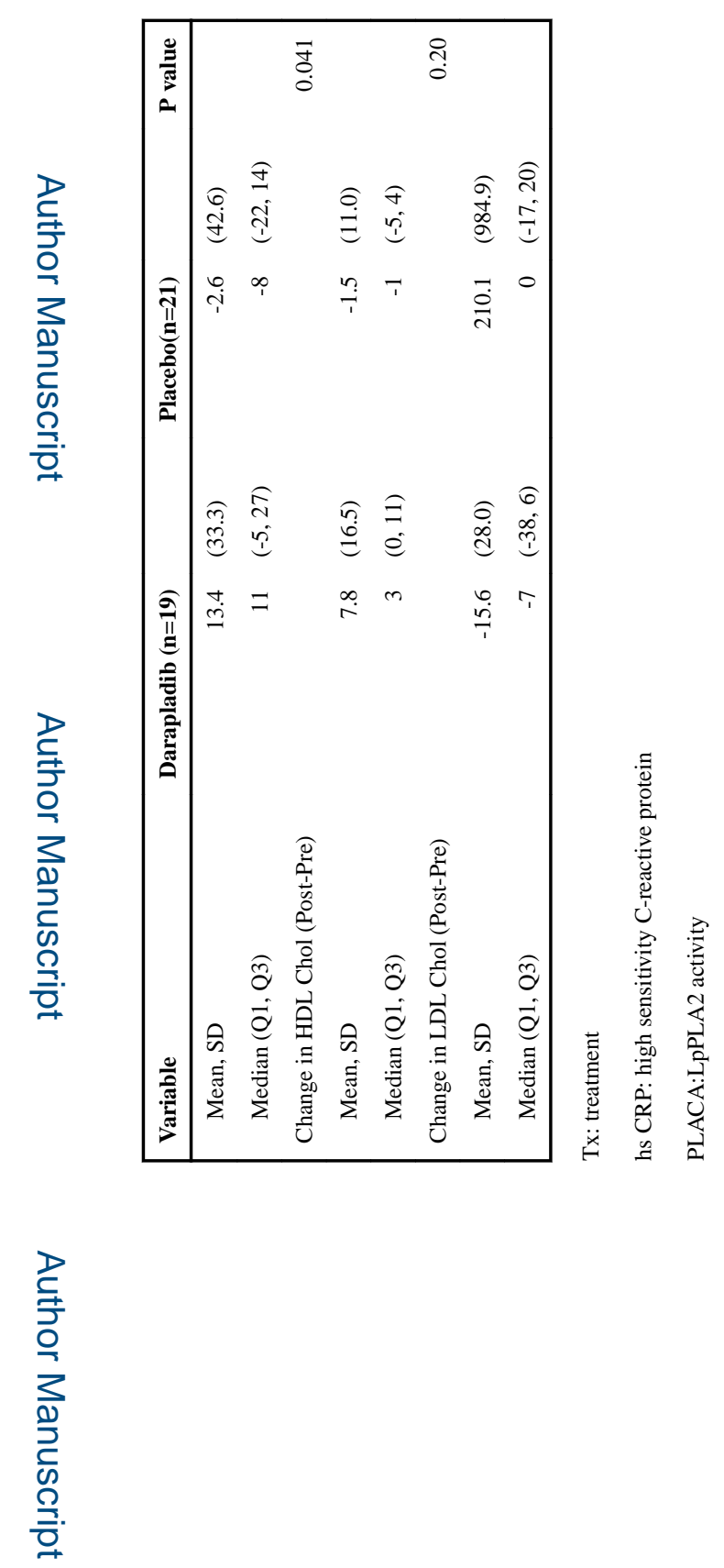

로을

Coron Artery Dis. Author manuscript; available in PMC 2019 March 01. 
Table 4

Measures of near infrared spectroscopy

\begin{tabular}{|c|c|c|c|}
\hline & Placebo(14) & Darapladib(11) & $P$ value \\
\hline \multicolumn{4}{|l|}{ LCBI } \\
\hline Baseline & $25.16[12.90,48.89]$ & $18.14[2.77,46.28]$ & 0.706 \\
\hline \multirow[t]{2}{*}{ Follow up } & $14.50[0.70,77.44]$ & $34.60[11.73,64.08]$ & 0.495 \\
\hline & 0.219 & 0.547 & \\
\hline \multicolumn{4}{|l|}{ Pull Back Length (mm) } \\
\hline Baseline & $56.92 \pm 16.30$ & $62.68 \pm 20.11$ & 0.450 \\
\hline \multirow[t]{2}{*}{ Follow up } & $55.91 \pm 16.84$ & $52.90 \pm 19.06$ & 0.587 \\
\hline & 0.998 & 0.547 & \\
\hline \multicolumn{4}{|l|}{ LCBI/L } \\
\hline Baseline & $0.37[0.19,0.83]$ & $0.23[0.04,0.84]$ & 0.641 \\
\hline Follow up & $0.20[0.01,1.23]$ & $0.57[0.29,1.39]$ & 0.270 \\
\hline & 0.578 & 0.383 & \\
\hline \multicolumn{4}{|l|}{$\operatorname{maxLCBI}_{4 \mathrm{~mm}}$} \\
\hline Baseline & $64.56[7.74,128.56]$ & $22.43[0,75.63]$ & 0.522 \\
\hline \multirow[t]{2}{*}{ Follow up } & $9.37[0,108.43]$ & $0.21[0.06,56.79]$ & 0.674 \\
\hline & 0.063 & 0.547 & \\
\hline \multicolumn{4}{|l|}{ Block Chemogram (\%) } \\
\hline \multicolumn{4}{|l|}{ Baseline } \\
\hline Red & $95.95[86.58,99.24]$ & $97.60[92.46,100]$ & 0.240 \\
\hline Orange & $0[0,6.35]$ & $0[0,3.20]$ & 0.604 \\
\hline Tan & $0[0,4.46]$ & $0[0,0]$ & 0.110 \\
\hline Yellow & $0[0,2.24]$ & $0[0,5.97]$ & 0.498 \\
\hline \multicolumn{4}{|l|}{ Follow up } \\
\hline Red & $95.78[75.86,100]$ & $91.80[80.04,96.30]$ & 0.459 \\
\hline Orange & $0[0,15.79]$ & $3.85[0,7.97]$ & 0.951 \\
\hline Tan & $0[0,8.82]$ & $3.58[0,9.98]$ & 0.346 \\
\hline Yellow & $0[0,2.85]$ & $0[0,3]$ & 0.750 \\
\hline Change in LCBI & $13.73[-0.96,36.04]$ & $0.72[-30.64,34.89]$ & 0.437 \\
\hline Percent change in LCBI & $100[56,100]$ & $63[-353,100]$ & 0.140 \\
\hline Change in $\mathrm{LCBI} / \mathrm{L}$ & $0.24[-0.14,0.69]$ & $-0.07[-0.71,0.65]$ & 0.331 \\
\hline Percent change in LCBI/L & $100[12,100]$ & $31[-420,100]$ & 0.208 \\
\hline Change in maxLCBI ${ }_{4 \mathrm{~mm}}$ & $65.32[5.44,126.04]$ & $22.43[-0.20,75.62]$ & 0.449 \\
\hline Percent change in maxLCBI ${ }_{4 \mathrm{~mm}}$ & $100[85,100]$ & $99[99,100]$ & 0.657 \\
\hline
\end{tabular}


Table 5

Virtual Histology Intravascular Ultrasound

\begin{tabular}{|c|c|c|c|}
\hline & Placebo(20) & Darapladib(19) & $p$ value \\
\hline \multicolumn{4}{|l|}{ Plaque Volume $\left(\mathrm{mm}^{3}\right)$} \\
\hline Baseline & $61.90[36.50,99.43]$ & $65.3[46.80,132.70]$ & 0.633 \\
\hline \multirow[t]{2}{*}{ Follow up } & $57.05[33.50,113.58]$ & $65.8[32.60,106.80]$ & 0.685 \\
\hline & 0.735 & 0.277 & \\
\hline \multicolumn{4}{|l|}{ Pullback Length (mm) } \\
\hline Baseline & $18.22 \pm 6.56$ & $16.94 \pm 5.65$ & 0.5459 \\
\hline \multirow[t]{2}{*}{ Follow up } & $15.74 \pm 6.47$ & $16.36 \pm 3.42$ & 0.7880 \\
\hline & 0.843 & 0.0429 & \\
\hline \multicolumn{4}{|l|}{ corrected PV $\left(\mathrm{mm}^{3} / \mathrm{mm}\right)$} \\
\hline Baseline & $3.13[3.69,4.34]$ & $4.53[4.16,6.67]$ & 0.070 \\
\hline \multirow[t]{2}{*}{ Follow up } & $3.60[3.11,5.81]$ & $4.45[3.08,6.79]$ & 0.443 \\
\hline & 0.358 & 0.421 & \\
\hline \multicolumn{4}{|l|}{ NC volume (\%) } \\
\hline Baseline & $8.70[1.55,18.93]$ & $15.3[4.15,21.20]$ & 0.209 \\
\hline \multirow[t]{2}{*}{ Follow up } & $6.00[1.50,15.30]$ & $10.7[3.75,21.00]$ & 0.234 \\
\hline & 0.835 & 0.915 & \\
\hline \multicolumn{4}{|l|}{$\mathrm{NC}$ volume $\left(\mathrm{mm}^{3}\right)$} \\
\hline Baseline & $0.2[0.08,4.70]$ & $1.5[0.20,11.5]$ & 0.297 \\
\hline \multirow[t]{2}{*}{ Follow up } & $0.5[0.05,0.25]$ & $0.4[0.10,15.60]$ & 0.478 \\
\hline & 0.441 & 0.880 & \\
\hline Absolute Change of corrected PV during treatment $\left(\mathrm{mm}^{3} / \mathrm{mm}\right)$ & $0.08[-0.44,0.51]$ & $0.11[-0.29,0.85]$ & 0.563 \\
\hline Percent change of corrected PV during treatment $(\%)$ & $2[-13,9]$ & $4[-5,14]$ & 0.376 \\
\hline Absolute change of $\mathrm{NC}$ volume during treatment $\left(\mathrm{mm}^{3}\right)$ & $0[-0.20,1.35]$ & $0[-2.00,3.00]$ & 0.738 \\
\hline Percent change of NC component during treatment (\%) & $19[-73,54]$ & $17[-29,75]$ & 0.376 \\
\hline
\end{tabular}

PV; plaque volume, NC; necrotic core 
Table 6

The results of optical coherence tomography

\begin{tabular}{|c|c|c|c|}
\hline & Placebo (11) & Darapladib (8) & p value \\
\hline \multicolumn{4}{|l|}{ Lipid-rich plaque (\%) } \\
\hline Baseline & $6(55)$ & $4(50)$ & 0.845 \\
\hline Follow up & $5(45)$ & $4(50)$ & 0.833 \\
\hline \multicolumn{4}{|l|}{ Lipid-rich plaque (Max. No, n) } \\
\hline Baseline & $1[0,1]$ & $1[0,3.25]$ & 0.597 \\
\hline \multirow[t]{2}{*}{ Follow up } & $1[0,1]$ & $0.5[0,1.75)$ & 0.791 \\
\hline & 1.000 & 1.000 & \\
\hline \multicolumn{4}{|l|}{ Lipid rich plaque angle $\left({ }^{0}\right)$} \\
\hline Baseline & $55.85[40.05,67.25]$ & $61.30[51.05,71.40]$ & 0.831 \\
\hline \multirow[t]{2}{*}{ Follow up } & $67.70[62.65,90.20]$ & $61.95[50.63,102.53]$ & 0.540 \\
\hline & 0.250 & 0.500 & \\
\hline \multicolumn{4}{|l|}{ Macrophage image (\%) } \\
\hline Baseline & $3(27)$ & $4(50)$ & 0.819 \\
\hline Follow up & $4(36)$ & $4(50)$ & 0.152 \\
\hline \multicolumn{4}{|l|}{ Macrophage angle, $\left({ }^{0}\right)$} \\
\hline Baseline & $39.30[30.00,40.70]$ & $49.45[42.70,56.20]$ & 0.083 \\
\hline \multirow[t]{2}{*}{ Follow up } & $34.70[26.75,38.75]$ & $50.00[26.00,70.73]$ & 0.337 \\
\hline & 0.500 & 0.625 & \\
\hline \multicolumn{4}{|l|}{ Macrophage Length (mm) } \\
\hline Baseline & $1.20[0.60,1.60]$ & $1.50[0.80,2.20]$ & 0.772 \\
\hline \multirow{2}{*}{ Follow up } & $1.60[0.75,2.08]$ & $1.00[0.90,1.95]$ & 0.665 \\
\hline & 1.000 & 0.375 & \\
\hline \multicolumn{4}{|l|}{ Microchannel (\%) } \\
\hline Baseline & $7(64)$ & $5(63)$ & 0.959 \\
\hline Follow up & $5(45)$ & $3(38)$ & 0.457 \\
\hline \multicolumn{4}{|l|}{ Microchannel (max number, n) } \\
\hline Baseline & $3[1.75,4.25]$ & $2[1,4]$ & 0.551 \\
\hline \multirow[t]{2}{*}{ Follow up } & $1.5[1,2.75]$ & $2[1,3]$ & 0.371 \\
\hline & 0.219 & 1.000 & \\
\hline \multicolumn{4}{|l|}{ Length (mm) } \\
\hline Baseline & $1.2[1.00,2.00]$ & $2.00[1.60,5.40]$ & 0.049 \\
\hline \multirow[t]{2}{*}{ Follow up } & $2.10[1.10,4.75]$ & $1.20[1.00,1.80]$ & 0.269 \\
\hline & 0.125 & 0.313 & \\
\hline Change in lipid core, $\mathrm{n}$ & $0.00[0.00,1.00]$ & $0[-0.25,1.25]$ & 0.836 \\
\hline Percent change in lipid core & $25[0,100]$ & $0[-10,75]$ & 0.537 \\
\hline Change in lipid core angle, ${ }^{\circ}$ & $-0.22[-40.30,48.70]$ & $0[-12.67,0.52]$ & 1.000 \\
\hline Percent change in lipid core angle & $-22[-59,100]$ & $-3[-42,3]$ & 1.000 \\
\hline Change in macrophage angle, ${ }^{\circ}$ & $0.0[-33.5,30.0]$ & $-30[-63.2,-2.7]$ & 0.165 \\
\hline Percent change in macrophage angle & $100[12,100]$ & $47[-3,75]$ & 0.800 \\
\hline
\end{tabular}

Coron Artery Dis. Author manuscript; available in PMC 2019 March 01. 


\begin{tabular}{|lccc|}
\hline & Placebo (11) & Darapladib (8) & p value \\
\hline Change in microchannel & $2.0[0.5,3.5]$ & $0[-1.0,0.25]$ & 0.066 \\
Percent change in microchannel & $66[0,90]$ & $0[-14,25]$ & 0.055 \\
Change in microchannel length & $-200[-2300,300]$ & $600[0,4400]$ & 0.055 \\
Percent change in microchannel length & $-17[-162,22]$ & $3[0,81]$ & 0.114 \\
\hline
\end{tabular}

